\title{
Sobreasseverações: manobras discursivas em notícias on-line
}

\author{
Surassertions: Discursive Maneuverings in Online News
}

\author{
André William Alves de Assis* \\ Universidade Federal de Minas Gerais \\ Belo Horizonte - Minas Gerais / Brasil \\ Sônia Aparecida Lopes Benites** \\ Universidade Estadual de Maringá \\ Maringá - Paraná / Brasil
}

\section{Resumo}

Neste trabalho, analisamos notícias on-line baseadas em relatos de fala. Essas notícias mostram-se ricas em sobreasseveraçôes, conceito que, de acordo com Maingueneau (2008), implica o destaque feito pelo próprio locutor do texto-fonte. Não raro, no funcionamento midiático, o lugar de sobreasseverador é imputado a um locutor que não efetuou aquele destaque no texto-fonte. Com o objetivo de identificar casos em que uma sobreasseveração é atribuída, à revelia, a um locutor, e categorizar as manobras discursivas visíveis nas sobreasseverações, analisamos a forma como são relatados dois debates político-televisivos em sete veículos on-line. Nossos resultados indicam a existência de dois tipos de manobras discursivas propiciadas pela construção da notícia on-line: o primeiro se evidencia em um processo de síntese; o segundo implica diversos graus de alteração na (re)produção de sentidos que recenografam os debates políticotelevisivos.

\footnotetext{
* assis.awa@gmail.com

**salbenites@gmail.com
} 


\section{Palavras-chave}

Sobreasseveração; citação; debate político; notícia on-line; manobras discursivas.

\section{Abstract}

In this research, we analyze online news based on speech reports. News are highly rich in surassertion which, according to Maingueneau (2008), imply highlighting by the locutor of the source-text. Within the context of social media functioning, overstatements are often ascribed to a locutor who, in fact, had not placed that special emphasis as reported in the source-text. In order to evaluate attributed surassertion, an analysis will be undertaken on the reporting of two Brazilian political TV debates in seven online newspapers. Results show two types of discursive maneuverings through the construction of online news: the first is a synthesis process and the second implies different degrees of changes in the (re)production of meanings that remake the scene of the TV political debates.

\section{Keywords}

Surassertion; quotes; political debate; online news; discursive maneuverings. 


\section{CONSIDERAÇÕES INICIAIS}

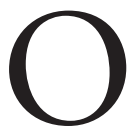

s pronunciamentos dos atores políticos não raro destacam fragmentos enunciativos curtos e singulares, destinados à repetição. Estrategicamente situados em final de texto ou de parágrafo, esses fragmentos condensam uma "tomada de posição" e constituem o que Dominique Maingueneau (2008, p. 77) denomina sobreasseveração.

A retomada desses fragmentos pelos textos noticiosos frequentemente apresenta manobras discursivas que os sintetizam, ampliam, diminuem ou simplificam. A configuração discursiva dessas retomadas é o objeto deste estudo, que focaliza as notícias on-line sobre dois debates político-eleitorais televisivos, com base nos desdobramentos da Análise do Discurso, na perspectiva de Maingueneau. Objetivamos analisar as notícias sobre o debate veiculadas por diversos sites, focalizando os recursos utilizados para alterar as sobreasseveraçóes e recenografar os debates.

O trabalho está dividido em três seções. Na primeira, tratamos da noção de sobreasseveração e de suas interfaces; na segunda, descrevemos os dados, para, na terceira, identificar e categorizar as manobras incidentes nas sobreasseverações.

\section{A NOÇÃO DE SOBREASSEVERAÇÃO}

Para tratar convenientemente da sobreasseveração, evocamos duas temáticas recorrentes da obra recente de Maingueneau, inextricavelmente relacionadas - a destacabilidade das enunciações e os regimes enunciativos. A destacabilidade é propiciada por certas características formais: "são curtas, bem estruturadas, de modo a impressionar, a serem facilmente memorizáveis e reutilizáveis"; são, além disso, "pronunciadas com o ethos enfático conveniente" e generalizações "que enunciam um sentido completo" (MAINGUENEAU, 2008, p.74-77). 
Os regimes enunciativos são dois: o aforizante e o textualizante. Ao primeiro pertencem os enunciados destacados, a aforização: "nem resposta, nem argumentação, nem narração, mas pensamento, dito, tese, proposição, afirmação soberana..."(MAINGUENEAU, 2010, p. 14). O"aforizador"é um "hiperenunciador", que se expressa como sujeito autorizado, atualizando sempre o "memorável", em retomadas que enunciam uma verdade, uma concepção de vida, uma doutrina. A enunciação aforizante coloca-se além dos limites impostos por um gênero específico - é livre, autônoma, generalizante, solene e carrega um sentido mais ou menos estabilizado.

Ao lado dos enunciados naturalmente "destacados", pertencentes ao regime aforizante, como as máximas, os provérbios e os slogans, Maingueneau (2010) identifica enunciados "destacáveis", isto é, passíveis de serem destacados de um discurso. Pertencentes ao regime textualizante, esses enunciados, as sobreasseverações, resultam de uma modulação do próprio texto, realizada pelo locutor do texto-fonte, por meio de um conector, de uma reformulação, ou de uma frase generalizante em posição final.

Afirmar que a sobreasseveração é destacada em um texto-fonte não significa que ela seja movida por uma intenção, uma vez que as notícias on-line são um produto coletivo da maquinaria midiática, sendo o"locutor do textofonte" a instância dada como responsável pelo texto. Quem faz a manobra de recortar, colar, trocar palavras é o site que retoma as palavras do locutor-fonte, e o sobreasseverador é aquele a quem é atribuída a fala destacada do texto.

\subsection{Sobreasseveração, cenografia e ethos}

Conforme Maingueneau (2006, p. 250), a cena da enunciação compreende três cenas de fala distintas e complementares: a "cena englobante", definida pelo tipo de discurso; a "cena genérica", definida pelo gênero; a "cenografia" que legitima o discurso.

A cena englobante "define a situação dos parceiros em certo quadro espaço-temporal” (MAINGUENEAU, 2011-a, p.86). No caso que analisamos, as notícias on-line abrangem as cenas englobantes do discurso político, ao reunir enunciados em torno do debate político-televisivo. Todavia, o texto é enunciado por meio de um gênero, a cena de fala genérica, que envolve "[...] um contexto específico: papéis, circunstâncias (em particular, um modo de inscrição no espaço e no tempo), um suporte material, uma finalidade, etc." 
(MAINGUENEAU, 2008, p. 116). As condições de enunciação do debate político-televisivo definem os papéis do moderador, dos atores políticos e do público (eleitor), enquanto as condições de enunciação da notícia on-line definem os papéis do enunciador, do jornalista e de um interlocutor (leitor).

Essas duas cenas definem o chamado "quadro cênico do texto", que especifica o espaço estável no interior do qual o enunciado adquire sentido. No entanto, não é com esse quadro cênico que o leitor se depara na enunciação, mas com a cenografia, "instituída pelo próprio discurso" (MAINGUENEAU, 2008, p.116) ${ }^{1}$. A cenografia não é, portanto, um lugar, um quadro, um espaço já construído, que existiria alheio ao discurso. Ela é, "ao mesmo tempo, a fonte do discurso e aquilo que ele engendra; ela legitima um enunciado que, por sua vez, deve legitimá-la” (MAINGUENEAU, 2011-a, p. 87-88).

Maingueneau denomina "incorporação" o momento em que o discurso faz o enunciador encarnar-se e o coenunciador aderir a seu papel na enunciação. Essa dupla incorporação insere enunciador e coenunciador em uma comunidade imaginária que evoca uma certa unidade discursiva e evidencia um tom, por meio de um ethos discursivo que se constrói na cenografia.

O ethos manifesta-se" como 'voz" e, além disso, como 'corpo enunciante', historicamente especificado e inscrito em uma situação, que sua enunciação ao mesmo tempo pressupõe e valida progressivamente" (MAINGUENEAU, 2011-b, p. 70). Nessa dimensão discursiva, o ethos se desdobra no registro do "mostrado", sendo sua eficácia decorrente do envolvimento com a cenografia, sem que isso seja explicitado.Dessa forma, "qualquer discurso escrito [...] possui uma vocalidade específica, que permite relacioná-lo a uma fonte enunciativa, por meio de um tom que indica quem o disse" (MAINGUENEAU, 2011b, p. 72).

\section{OS DADOS DE ANÁLISE}

Nossos dados compreendem dois diferentes gêneros discursivos: debate político-televisivo e notícia on-line. Os debates envolveram os candidatos à presidência da República brasileira, Dilma Rousseff e José Serra, e foram veiculados pelas redes Bandeirantes e Globo de televisão, no segundo turno das eleições de 2010. Transcritos de vídeos em formato digital, esses debates são os textos-fonte das notícias on-line, veiculadas, no dia seguinte aos confrontos, nos sites e portais ${ }^{2}$ de Carta Capital, Correio Braziliense, Band, Época, UOL, Veja e Terra. 


\subsection{O debate político na TV}

Charaudeau (2000, p. 97) concebe o gênero debate político-televisivo como

[...] uma forma de diálogo organizado de forma a fazer surgir a verdade, seja qual for a sua configuração, a propósito de um tema problematizado, através da confrontação de saberes diferentes sobre o tema, por intermédio de um dispositivo televisivo (organização, gestão, apresentação) que permite que a exposição destes saberes e a sua confrontação desvendem certos aspectos da problematização, tornando-os, ao mesmo tempo, o mais inteligíveis possível.

O confronto, as temáticas, e os atores que promovem o diálogo relacionamse com o contexto histórico em que o debate se inscreve. No presente caso, ambos foram ao ar em 2010, no segundo turno das eleiçóes para presidente. $\mathrm{O}$ da Band, em 10 de outubro de 2010, foi o primeiro debate do segundo turno dessas eleições; o da Globo, em 29 de outubro de 2010, foi o último, antes das eleições.

Os dois debates operam lógicas diferentes na seleção de perguntas e respostas. Diferem na forma de organização do espaço, de cena no sentido estrito, mas se caracterizam "por uma tendência para se colocar ao serviço do diálogo" (CHARAUDEAU, 2000, p. 95) e determinam três importantes papéis na cena genérica: os moderadores, os atores políticos e o público.

Os moderadores, dentro da cena genérica, esclarecem as regras do programa, controlam o tempo dos candidatos, concedem e retiram o direito à palavra, introduzem temas e perguntas e julgam, juntamente com uma equipe, se um candidato foi agredido, concedendo-lhe direito de resposta. $\mathrm{O}$ moderador é o responsável imediato por impor as coerções do rito genético ${ }^{3}$ dentro da cena construída no debate.

Os atores políticos, José Serra e Dilma Rousseff, confrontam-se, trocam constantemente de lugar, num jogo de posiçôes que envolve resposta a uma pergunta, com direito à réplica e à tréplica. "Ao tomar a palavra, cada participante institui-se como locutor, convocando vozes ou enunciadores que usa estrategicamente para a construção do seu ethos" (BRAGA, 2006, p. 9) e da cena da enunciação.

O debate da Band segue a regra geral, em que o público atua apenas como expectador, enquanto,no programa da Globo, o público participa diretamente; 
porém, o direito à palavra se restringe à leitura de perguntas sorteadas, que não podem ser modificadas pelo participante. Ainda que o papel do público possa parecer passivo, ele representa os eleitores, dentro da cena enunciativa. Sua presença pode causar desconforto aos atores políticos, que devem se dirigir aos presentes e às câmeras. Dessa forma, a argumentação dos atores políticos precisa ser duplamente eficaz.

O estúdio da Band dispõe-se em forma de semicírculo, com uma grande tela ao fundo. Os atores políticos encontram-se frente a frente e o mediador ao fundo, de frente para os candidatos e de costas para o público. Este encontrase espacialmente atrás do mediador, o que lhe confere acesso somente às faces dos candidatos.

O estúdio da Globo tem formato circular e os candidatos, inicialmente, ficam um ao lado do outro. As tribunas posicionam-se de frente para o público, e não para o adversário; permite-se que os atores políticos se movimentem pelo palco e dirijam as respostas àqueles que leem as perguntas, os eleitores dados como indecisos.

Quanto aos temas, segurança pública e saúde foram abordados nas duas emissoras. O debate da Band focalizou também a privatização da Petrobrás, infraestrutura, programas sociais e calúnias. $\mathrm{Na}$ Globo, abordou-se: política social, funcionalismo público, agricultura, corrupção, saneamento, educação, legislação trabalhista, meio ambiente, impostos e previdência.

A Band dividiu o programa em cinco blocos, em que os candidatos responderam a perguntas feitas pelo mediador e pelo adversário, com tempo para resposta, réplica e tréplica. $\mathrm{Na}$ Globo, os candidatos sorteavam eletronicamente o tema. Em seguida, o moderador escolhia, por sorteio, o candidato. $\mathrm{O}$ mesmo método era utilizado na seleção de um dos doze eleitores indecisos, procedentes de todo o país. O eleitor lia a pergunta, que, após respondida, era seguida de réplica e tréplica.

A estruturação do debate da Band impedia a participação direta dos convidados na cenografia do debate; já no debate da Globo, os eleitores indecisos faziam parte da cena da enunciação, o que fez com que o discurso dos atores políticos focalizasse mais explicações e detalhamento de propostas do que críticas.

A participação do público mudou a cenografia do debate da Globo, o que também resultou em mudança na relação entre os candidatos, que não se 
confrontaram. A cenografia da Globo propiciou que os candidatos diferissem muito pouco do perfil apresentado nos programas gratuitos do Horário Político cotidiano. Dessa forma, os atores políticos resumiram suas falas à apresentação de propostas impostas pelo tema apresentado, o que justifica a discrepância quantitativa entre as temáticas levantadas nos dois debates.

O número de notícias on-line sobre o debate da Globo foi menor que o da Band, uma vez que ele foi ao ar apenas dois dias antes da data da eleição, quando era proibida a veiculação de propaganda ou de textos que pudessem ser considerados propaganda política. Isso justifica a maior ocorrência de sobreasseverações retiradas de notícias veiculadas sobre o debate da Band.

\subsection{A notícia on-line}

O jornalismo online, ao reproduzir os acontecimentos da última hora, seleciona-os e elabora a notícia, interferindo, durante esse processo, no funcionamento das sobreasseverações que são constitutivas dessa notícia.

Como lembra Nogueira (2003, p. 164-165), a notícia on-line exibe a "coexistência de diversos elementos: imagens fixas, texto, manchas gráficas, logotipos, ícones, imagens animadas, etc. [...] percebemos então que a lógica da apresentação da informação na internet deve mais ao design gráfico e à tipografia" (NOGUEIRA, 2003, p. 160).

Dessa maneira, a notícia on-line faz emanar, a partir da notícia "tronco", notícias laterais, que são "os galhos" interligados por meio de outra característica da notícia on-line, os hiperlinks, dispostos na página em que as notícias são veiculadas. Estes são caminhos que direcionam os leitores às notícias disponíveis, permitindo ao usuário ir e vir, optar por caminhos diferentes de leituras entre os "galhos".

A rapidez da notícia on-line transforma o hiperlink em um recurso que pode funcionar como efeito de compromisso com a verdade, já que seu uso pode direcionar o leitor para o local que comprove a notícia (vídeo, áudio, imagem, outra publicação, etc.). Esse texto não sequencial é um diferencial da notícia on-line, que permite à leitura fugir, mais ou menos, às coerções interpretativas que o gênero impresso poderia impor.

As notícias on-line que nos servem de corpus não possuem links direcionados a vídeos; algumas possuem "galhos" que compõem a grande "árvore de notícias". No entanto, o tratamento dado à sobreasseveração feita pelo 
autor da fala relatada parece ter papel fundamental no processo de construção das notícias on-line analisadas, o que permite observar esse processo como característica desse gênero. Elaboramos, a seguir, uma breve contextualização histórica da autoimagem desses veículos.

O portal Universo On-line (UOL), integrante do Grupo Folha, está no ar desde 1996. Inicialmente, trouxe os serviços de "bate-papo" e a edição diária da Folha de S. Paulo, além de reportagens do The New York Times traduzidas para o português. Atualmente, conta com o maior número de acessos por internautas brasileiros. Afirma ter como princípios "Produzir informação e análise jornalísticas com credibilidade, transparência, qualidade e agilidade"

Carta Capital foi fundada em 1994, pelo jornalista Mino Carta, participante ativo da imprensa brasileira nos últimos quarenta anos. Atualmente, é ele o redator chefe da revista. O site da revista, disponibilizado em 2004, tem uma proposta "calcada no tripé do bom jornalismo baseado na fidelidade à verdade factual, no exercício do espírito crítico e na fiscalização do poder onde que se manifeste"5. Em 2010, a revista explicitou o posicionamento favorável à candidatura de Dilma Rousseff. ${ }^{6}$

A revista Veja pertence ao Grupo Abril, o maior da América Latina. Lançada em 1968, é a revista de maior circulação no Brasil e a terceira no mundo. Veja.com, portal da revista, afirma ter os mesmos princípios editoriais da revista impressa: "independência, isenção, responsabilidade jornalística e a defesa intransigente dos interesses do Brasil"”.

O canal da rede Bandeirantes (Band) integra o Grupo Bandeirantes e está no ar desde os anos 80 , época envolta em coerções da ditadura no Brasil. Afirmando calcar-se nos pilares de credibilidade e independência, o noticiário da Band pretende-se crítico, opinativo e independente. A emissora foi a primeira a promover debates políticos, o que a leva a se considerar "sinônimo de tradição em debates políticos"8.

Terra Networks S.A é uma companhia multinacional espanhola que comprou em 1999 a empresa brasileira NutecNet e implantou no Brasil uma das filiais de seu portal Terra, o segundo mais acessado no Brasil. Terra é a maior empresa latino-americana de mídia on-line. Seus princípios estão "baseados no tripé Notícias-Entretenimento-Esportes".

A revista Época pertence às Organizações Globo. Fundada em 1998,já nasceu digital e trouxe para o país o estilo de notícias úteis ou news you can 
use, estilo de reportagem americano e europeu que aplica uma visão otimista em relação às notícias que veicula ${ }^{10}$. Afirma praticar um "jornalismo investigativo, com informação, detalhamentos e análises das diversas frentes que compõem todo e qualquer fato" 11 .

Correio Braziliense é a marca de um periódico impresso, fundado por Assis Chateaubriand, em 1960. Pertencente ao grupo Diários Associados, o jornalismo do Correio Braziliense passou a investir em novas mídias, por meio do portal Correio Web, disponível desde 1996. O site do jornal foi lançado somente em 2008. ${ }^{12}$

\section{ANÁLISE DAS SOBREASSEVERAÇÕES EM NOTÍCIAS ON-LINE}

Identificamos, nas retomadas de sobreasseveração pelas notícias online, duas modalidades de manobras: as sintetizadoras, que efetuam uma síntese avaliativa do debate, e as modificadoras, que promovem alteração do sentido.

\subsection{Manobras sintetizadoras}

\subsubsection{Título sintetizador}

Os títulos são interpretações que se processam por um movimento de síntese do debate e constroem cenografias diversas por meio do tom do discurso. Simultaneamente, constroem uma cenografia e marcam posicionamentos em relação aos candidatos. As escolhas lexicais, a opção por evidenciar ou apagar os sujeitos políticos indiciam interpretações possíveis dos posicionamentos de cada uma das revistas no discurso, pois o tom por elas empregado na sobreasseveração que serve de título "constitui [...] uma dimensão que faz parte da identidade de um posicionamento discursivo" (MAINGUENEAU, 2011b, p. 72):

CARTA CAPITAL: No $1^{\circ}$ debate, Dilma reage e dá novo tom à campanha no $2^{\circ}$ turno. (Band)

BAND: Serra e Dilma trocam ataques durante o debate da Band. UOL: Petistas comemoram e tucanos criticam estratégia de Dilma. 
VEJA: Debate na televisão renasceu neste domingo.

TERRA: No debate mais duro da eleição, Dilma e Serra trocam acusações.

Sem destacar candidatos, em seu título, Veja sobreassevera o evento político como o renascimento do debate televisivo, sem informar o motivo deste. Ao optar por não destacar o desempenho de um ou outro candidato no embate, VEJA apresenta, inicialmente, um ethos de isenção e neutralidade.

Os títulos das matérias dos outros veículos, ao contrário, põem em relevo uma tomada de posição. Carta Capital resume o debate como uma reação que resulta em "novo tom" da campanha, como consequência da reação de Dilma Rousseff. Similarmente, a síntese de UOL apresenta a candidata como vencedora. O enunciado "tucanos criticam estratégia de Dilma" possibilita a interpretação de que Serra teria perdido o debate, ocasionando a crítica à estratégia adversária.

A Band sobreassevera como "ataque" o debate entre os dois atores políticos, apontando para a cenografia de luta que será construída no discurso. A mesma cenografia está presente no portal Terra, que póe em relevo os dois candidatos, direcionando a interpretação para uma troca de acusações entre eles.

\subsubsection{Interpretação da fala}

Outro processo de síntese se processa sobre as falas dos atores políticos, numa interpretação que assume uma tomada de posição em relação ao debate televisivo:

DILMA ROUSSEFF: [...] inclusive eu acho estranho você [José Serra] dizer certas coisas, porque você regulamentou o acesso ao aborto no SUS. Então, veja bem, eu sou acusada de coisas que eu inclusive não vou gostar de mencionar, pela sua própria esposa, sendo que você, você regulamentou, até eu concordo com a regulamentação, porque eu sou contra tratar a questão das mulheres, das duas mulheres que morrem por dia ou um dia sim um dia não, por aborto, como uma questão de polícia. Entre prender e atender, eu fico com atender. (Band)

VEJA: No passado, [Dilma] manifestou-se claramente em defesa da descriminalização do aborto, em diversas ocasiōes. Ao constatar que 
isso lhe tirou os votos de um bom número de católicos e evangélicos, ela inverteu o seu discurso sobre o tema. No debate, Dilma retomou esse tipo de declaração, mas pautou-se, sobretudo, pela máxima de que o ataque é a melhor defesa.

CARTA CAPITAL: Desde o início da polêmica, Serra vem dizendo que Dilma defende o aborto, mas a candidata insistiu e mostrou que ela defende é que ele deixe de ser considerado crime, pois coloca milhares de mulheres pobres sob risco de morte.

BAND: O tucano declarou também que Dilma não mostra suas posições, como sua visão sobre a descriminalização do aborto. A petista rebateu respondendo que, para ela, o tema deve ser tratado como questão de saúde pública.

Observamos que o site Veja abandona a neutralidade simulada no título, produzindo um discurso contrário à candidata petista. A pretexto de contextualização, a revista acrescenta à notícia a informação de que Dilma "no passado, manifestou-se claramente em defesa da descriminalização do aborto, em diversas ocasiōes", interpretação que altera a fala da candidata.

A sobreasseveração "Entre prender e atender, eu fico com atender" é interpretada por Veja como equivalente a "pautou-se, sobretudo, pela máxima de que o ataque é a melhor defesa”. Substitui-se, portanto, uma sobreasseveração construída pela enunciadora para sintetizar seu posicionamento, por uma aforização que reduz um discurso voltado ao aspecto social à máxima que concentra sentidos de ataque, de luta. A seleção e o tom das informações adicionais dadas pela revista direcionam a interpretação do leitor.

A sobreasseveração da candidata também foi alvo de interpretação pela revista Carta Capital. Ao afirmar que Dilma "insistiu e mostrou que ela defende é que ele [o aborto] deixe de ser considerado crime", opera-se uma alteração na sobreasseveração, com base na consideração de que atender mulheres que praticam o aborto é deixar de considerá-lo crime. A revista acrescenta à fala de Dilma que a prática do aborto "coloca milhares de mulheres pobres sob risco de morte".

A candidata não caracteriza as mulheres que morrem por dia, como faz Carta Capital. A interpretação sobre quem pratica o aborto e precisa ser atendido por correr risco de morte é uma construção da revista: "milhares de mulheres pobres". O posicionamento da revista não é de defesa do gênero, mas social, pois insinua que aquelas que podem pagar um aborto têm um acesso seguro a ele. As pobres perecem. 
A Band, que também alterou a sobreasseveração, interpretou a fala de Dilma como "tema [que] deve ser tratado como questão de saúde pública". A interpretação incide sobre todo o contexto que a sobreasseveração engendra. Porém, a BAND produz uma outra sobreasseveração, em resposta à crítica de José Serra que, ao contrário de Dilma, supostamente preferiria prender.

\subsubsection{Aproximação de frases}

A aproximação de trechos do texto, que estão distantes dentro da enunciação do debate é outra manobra discursiva que visa alterar as declarações, a pretexto de síntese:

DILMA ROUSSEFF: Eu acho, Serra, que você tem que ter cuidado pra não ter mil caras, porque a última mentira e calúnia contra mim ocorreu no caso em que vocês diziam que nós, a minha campanha tinha aberto o sigilo. E ai o que aconteceu, há hoje uma denúncia em que você, o Juiz te denunciou e você hoje é réu por calúnia, pelo crime de calúnia e difamação. Então, você se cuida porque você está dando os primeiros passos pra entrar na questão da ficha limpa. (Band, grifos nossos)

$\boldsymbol{V E J A : ~ " V o c e ̂ ~ p r e c i s a ~ t e r ~ c u i d a d o ~ p a r a ~ n a ̃ o ~ t e r ~ m i l ~ c a r a s , ~ e s t a ́ ~ s e n d o ~}$ processado por calúnia."

A síntese realizada por Veja resulta da junção de duas partes do texto e do apagamento do trecho que vem após a primeira.Após o alerta inicial, "Você tem que ter cuidado para não ter mil caras", omite-se um trecho e se substitui "você hoje é réu por calúnia" por "está sendo processado por calúnia”. Embora "ser réu" e "ser processado" tenham sentidos semelhantes, o apagamento é significativo, se considerarmos que a sobreasseveração está entre aspas, indicando que a fala da candidata teria sido exatamente essa. A utilização das aspas é uma manobra específica dessas alterações, que atribuem ao outro a responsabilidade do dizer resultante da síntese do jornal. 


\subsection{Manobras modificadoras de sentido}

\subsubsection{Mudança de tom}

Há situações em que, para se adequar ao posicionamento dos veículos de informação, procede-se ao apagamento de uma sobreasseveração realizada no calor da indignação, substituindo-a por um relato neutro e objetivo:

DILMA ROUSSEFF: [...] Agora, o que não está certo, por exemplo, é a sua esposa, a dona Mônica Serra, eu vou dizer o que ela falou, ela disse "a Dilma é a favor da morte de criancinhas", é tão absurda a acusação que mostra a característica desse processo, dessa campanha que é uma campanha contra mim e que usa uma coisa que o Brasil não tem, o ódio. (Band)

TERRA: A candidata do PT concluiu seu ataque afirmando que esse tipo de tratamento traz para o Brasil algo que não é da característica do brasileiro.

A fala de Dilma volta-se contra a acusação da esposa de José Serra, num tom de vitimização, o que é confirmado quando a candidata atribui àquele discurso o "ódio", relacionando essa cenografia aos ataques a ela direcionados. A sobreasseveração de Terra dá à notícia um tom de ataque, que inverte o tom e a cenografia. Enquanto a sobreasseveração de Dilma acentua que o ódio é uma "coisa que o Brasil não tem", o portal Terra fala em "algo que não é da característica do brasileiro".

O ódio, na fala de Dilma, supostamente, caracterizaria um estrangeiro, no caso, a chilena Mônica Serra. A cenografia de vítima enfatiza um discurso do tipo incontestável, calcado no estereótipo do brasileiro cordial. Porém, a informação dada pelo portal Terra altera a fala de Dilma e recenografa esse momento do debate.

\subsubsection{Transformação de declaração em interrogação}

A transformação de uma frase afirmativa em um questionamento é outra manobra que pode incidir em uma sobreasseveração, como vemos em: 
DILMA ROUSSEFF: [...] eu sou contra tratar a questão das mulheres, das duas mulheres que morrem por dia ou um dia sim um dia não, por aborto, como uma questão de polícia. Entre prender e atender, eu fico com atender. (Band, grifo nosso)

CARTA CAPITAL: "O que vamos fazer com essas mulheres, atender ou prender?"

A fala da candidata é uma sobreasseveração que afirma sua preferência por atender a prender. $\mathrm{O}$ tom de assistencialismo remete a políticas públicas que amparem mulheres que praticaram o aborto. A sobreasseveração, que já beneficia a circulação desse enunciado, é modificada pela Carta Capital, ao substituir o discurso afirmativo por um interrogativo. No entanto, a sobreasseveração não perde sua força. Além do efeito de maior adesão, a pergunta de Carta Capital conclama o leitor a participar da afirmação da candidata, assumindo a mesma opção dela e da revista, o que é indiciado na mudança de sujeito. Na versão da revista, Dilma, que havia falado em seu próprio nome, passa a ser um entre os interlocutores que devem decidir o que fazer, numa manobra que busca a adesão dos eleitores, ao mesmo tempo em que argumenta contra as críticas de Serra sobre o aborto. A mesma manobra de coparticipação do eleitor não se processa no exemplo a seguir:

JOSÉ SERRA: Sabe qual seria o Brasil do PT? O Brasil do orelhão, é o que a Dilma e o que seus amigos teriam feito caso tivessem o governo naquela época, porque ninguém teria celular. (Band)

CARTA CAPITAL: "A era do PT seria a era do orelhão".

BAND: Para o tucano, sem a privatização da telefonia, o Brasil seria ainda o "país do orelhão".

Aqui, a questão que José Serra levanta é respondida por ele próprio. Tanto Band quanto Carta Capital produzem sobreasseverações sobre essa fala:"A era do PT seria a era do orelhão" e "o Brasil seria ainda o 'país do orelhão"”. Contudo, a força pragmática do exemplo anterior, com o "nós inclusivo", é maior que o que ora ocorre, em que há apenas a mudança no tipo de frase. 


\subsubsection{Mudança de topicalização}

A mudança de topicalização propicia a destacabilidade de um termo, dentro de um enunciado, ao colocar em primeiro plano o que é tido como mais importante:

DILMA ROUSSEFF: é tão absurda a acusação que mostra a característica desse processo, dessa campanha que é uma campanha contra mim e que usa uma coisa que o Brasil não tem, o ódio. (BAND)

CARTA CAPITAL: "Isso é ódio, coisa que o Brasil não tem".

Ao topicalizar o "ódio", Carta Capital enfatiza a interpretação sobre essa não ser uma característica do brasileiro, e altera o tom do discurso, intensificando-o, uma vez que a palavra ódio, por si só, possui uma força expressiva que é diminuída em posição final.

\subsubsection{Transformação de aforização em sobreasseveração}

Nas notícias on-line analisadas, por vezes, transforma-se em sobreasseveração uma aforização. Observemos:

JOSÉ SERRA: Olha é só chegar campanha eleitoral o PT volta sempre com essa história, só que ele é, como se dizia no Chile, como padre Gatica: predica e não pratica. (Band)

TERRA: "O PT predica, mas não pratica", disse.

O provérbio chileno"Padre Gatica: predica e não pratica" equivale ao "Faça o que eu digo e não o que eu faço", do português. Sua atribuição ao partido da adversária produz um efeito de sentido de falsidade, pois implica que a filosofia por ele propalada não seria condizente com as atitudes de seus membros. A substituição de "Padre Gatica" por "PT" transforma uma aforização em uma sobreasseveração que não é dada no discurso-fonte, mas no texto da notícia. Fato semelhante ocorre no exemplo abaixo: 
DILMA ROUSSEFF: [...] o professor pra ser valorizado, ele precisa de ganhar bem, e mais, ele precisa de ter formação continuada. Não se pode, também, estabelecer com o professor uma relação de atrito quando o professor pede melhores salários, recebê-los com cassetetes ou interromper o diálogo. O diálogo é fundamental no respeito a essa profissão. (GLOBO)

ÉPOCA: Dilma aproveitou para atacar Serra quando ambos foram questionados sobre educação. Como já havia feito em outros debates, lembrou a relação crítica do governo do PSDB com a categoria, e a repressão às greves. "Não há diálogo ao se receber professor com cassetete".

"Não há diálogo ao se receber professor com cassetete" é uma sobreasseveração atribuída à candidata pela revista Época, em substituição à que fora por ela produzida: "O diálogo é fundamental no respeito a essa profissão". A comparação entre ambas, porém, mostra que o fragmento atribuído à candidata é mais enfático que o produzido por ela.

\section{CONSIDERAÇÕES FINAIS}

Os enunciados em destaque fazem parte do mecanismo de uma sofisticada e complexa maquinaria midiática, que produz e põe em circulação notícias on-line. As seleções e torções efetuadas pelos veículos de informação na construção das notícias evidenciam posicionamentos e cumprem uma necessidade pragmáticodiscursiva de adequação da enunciação à cenografia construída pela notícia e ao ethos do veículo.

Como observamos, as manobras discursivas incidentes na construção da notícia on-line recenografam os debates político-televisivos. Considerando que o leitor não possui acesso ao texto-fonte, mesmo que os hiperlinks o direcionem para os vídeos dos debates, a comparação entre o acontecimento discursivo e a interpretação da sobreasseveração é praticamente impossível. 


\section{NOTAS}

${ }^{1} \mathrm{O}$ evento discursivo debate político-eleitoral, por exemplo, pode desenrolar-se em uma cenografia de luta ou de sabatina.

${ }^{2}$ As distinções entre site e portal são ignoradas neste artigo. Interessa-nos apenas que se trate de notícias on-line.

${ }^{3}$ Como Maingueneau (2006, p. 155), "falamos em ritos genéticos para designar as atividades mais ou menos rotineiras através das quais se elabora um texto”.

${ }^{4}$ Disponível em: http://www1.folha.uol.com.br/institucional/missao.shtml. Acesso em: 01 maio 2012.

${ }^{5}$ Disponível em: http://www.cartacapital.com.br/sobre-cc/. Acesso em: 01 maio 2012.

${ }^{6} \mathrm{O}$ editorial com título "Por que apoiamos Dilma" foi publicado em 30 de setembro de 2012 no site da revista. Disponível em: http://www.cartacapital.com.br/politica/ por-que-apoiamos-dilma/. Acesso em: 01 maio 2012.

${ }^{7}$ Disponível em: http://www.publiabril.com.br/upload/files/0000/0857/M_dia_Kit_ Veja_Digital.pdf. Acesso em: 01 maio 2012.

${ }^{8}$ Disponível em: http://www.band.uol.com.br/grupo/jornalismo.asp. Acesso em: 01 maio 2012.

${ }^{9}$ Disponível em: http://pt.wikipedia.org/wiki/Terra_Networks. Acesso em: 01 maio 2012.

${ }^{10}$ Informação disponível em: http://corp.editoraglobo.globo.com/historia/. Acesso em 01 maio 2012.

${ }^{11}$ Disponível em: http://epoca.globo.com/midiakit/arquivos/MidiaKit_Epoca_2012-PT.pdf. Acesso em 01 mai 2012.

${ }^{12}$ Disponível em: www.diariosassociados.com.br/home/veiculos.php?co_veiculo=14. Acesso em 01 mai 2012.

\section{REFERÊNCIAS}

ASSIS, A. W. A. Citações e sobreasseveraçôes: o funcionamento da retomada de falas em notícias online [dissertação de mestrado]. Maringá: UEM, 2013.

BRAGA, D. Prós e Contras: o debate político televisivo como sub-género/sub-tipo de interacção verbal. Revista Galega de Filoloxía, 7: 29-65, A Coruña, 2006.

CHARAUDEAU, P. A palavra confiscada. Lisboa: Instituto Piaget, 2000. 
MAINGUENEAU, D. Discurso literário. São Paulo: Contexto, 2006.

.Cenas da enunciação. São Paulo: Parábola, 2008.

. Doze conceitos em análise do discurso. São Paulo: Parábola, 2010. . Análise de Textos de Comunicação. 6. ed. São Paulo: Cortez, 2011-a. . Ethos, cenografia, incorporação. In: AMOSSY, R. (Org.). Imagens de si no discurso: a construção do ethos. Trad. Dilson Ferreira da Cruz, Fabiana Komesu e Sírio Possenti. São Paulo: Contexto, 2011-b, p. 69-92.

NOGUEIRA, L. Jornalismo na rede: arquivo, acesso, tempo, estatística e memória. In: FIDALGO, A.; SERRA, P. (Orgs.). Informação e Comunicação Online, Volume I - Jornalismo Online. Covilhã: Universidade da Beira Interior, 2003, p. 159-169. 
